\title{
PREVALENCE OF HELICOBACTER PYLORI IN PATIENTS OF GASTRIC CARCINOIMA
}

KEY WORDS:

\section{Dr Sandeep Chandrakar}

Dr Rajendra Ratre

Dr Nitish Kumar

Rai

Dr T Narasimha

\section{Murty}

Professor And HOD, Department Of General Surgery, Atal Bihari Vajpayee Memorial Medical Collage Rajnandgaon (CG)

Associate Professor, Department of General Surgery, Pt JNM Medical College And Dr B R Ambedkar Memorial Hospital, Raipur( CG)

Senior Resident, Department of General Surgery, RSDKS GMC Ambikapur (CG)

PG Resident, Department of General Surgery, Pt JNM Medical College And Dr B R Ambedkar Memorial Hospital, Raipur( CG)

INTRODUCTION : $H$. pylori is a gastric pathogen that colonizes approximately $50 \%-60 \%$ of the world's population. Infection with $\mathrm{H}$. pylori causes chronic inflammation and significantly increases the risk of developing duodenal, gastric ulcer disease and gastric carcinoma. This study is undertaken to determine the clinical and pathological profile of gastric carcinoma in our institute and to find out the prevalence of $H$. pylori infection in gastric carcinoma patients. MATERIALS AND METHODS :We conducted our study in the Department of Surgery, Dr. B. R. A. M. Hospital, Raipur, C.G. over a period of 18 months. It was a hospital based, cross-sectional observational study. During upper GI endoscopy, site of the lesion and macroscopic type of the lesions were identified and recorded. Multiple tissue biopsy samples (>10) were collected from non-necrosed region of cancer. One piece of each paired specimen were immediately subjected to RapidUrease Test dry kit (RUT) for detection of Helicobacter pylori. Further these biopsy specimens were subjected to modified giemsa staining and culture.

RESULTS : Out of the 70 cases of gastric carcinoma, the prevalence of H.pylori was $64.28 \%$.The most common age group associated with gastric carcinoma with H.pylori infection was more than 60 years. There was male predominance seen for both gastric carcinoma and gastric carcinoma positive for H.pylori infection. The most common lesion for gastric carcinoma and those positive for H.pylori was ulceroproliferative type. The most common site of stomach involved in cases of Gastric carcinoma associated with H.pylori infection was antrum+pylorus of stomach. The most common histological type of gastric carcinoma associated with $\mathrm{H}$.pylori infection was poorly differentiated adenocarcinoma CONCLUSION : On the basis of our study it is evident that H.pylori is an independent risk factor for gastric carcinoma. .Infection with $\mathrm{H}$. pylori causes chronic inflammation and significantly increases the risk of developing duodenal, gastric ulcer disease and gastric carcinoma.

\section{INTRODUCTION:-}

Gastric carcinoma is one of the commonest malignancy which accounts for $9.7 \%$ of the total deaths among all cancers. ${ }^{1}$. It is twice more common in males as compared to females. ${ }^{1}$ At present, it is more common in Asian population more in China and India than in the United State of America (USA) or Europe. It is estimated that by the year 2020, approximately 50,000 new Gastric carcinoma cases will be reported annually in India. A study conducted in Karnataka reported gastric carcinoma to be among the five most common cancers even in young Indian men and women (aged 15-44 years) ${ }^{2}$. Due to its variability in incidence with place and generation, it has been considered that environmental factor rather than genetic factors determine the incidence of gastric carcinoma. H.pylori has been classified as a Class I carcinogen for Gastric carcinoma in 1994 by the International Agency of Cancer. ${ }^{3}$ This bacterium is then thought to be one of the causal factors in the development of Gastric carcinoma. It colonizes the stomach of nearly $50 \%-60 \%$ of the world's population ${ }^{4}$. $H$. pylori infection causes chronic inflammatory reaction thereby increasing the risk of duodenal ulcer, gastric ulcer disease and gastric carcinoma. It is one of the strongest known risk factor for development of gastric carcinoma ${ }^{2}$. This study was undertaken to determine the clinical and pathological profile of gastric carcinoma in our institute and to find out the prevalence of $H$.pylori infection in gastric carcinoma patients.

\section{MATERIAL AND METHODS}

We conducted our study in Department of Surgery, Dr. B. R. A. M. Hospital, Raipur, C.G. over a period of 18 months. Written informed consent was taken from all the patients. This study was hospital based, cross-sectional observational study. www.worldwidejournals.com |
Inclusion criteria of study was

- All patients diagnosed as gastric carcinoma by gastric biopsy.

Exclusion Criteria

- Patients with gastric carcinoma who had taken complete course of antibiotics for eradicatiton of $\mathrm{H}$ pylori

People with debilitating end stage illness unfavouring gastric biopsy were excluded from study The detailed history of all the patients was collected inclusive of the duration of complaints (epigastric pain or burning, abdominal lump, vomiting, early satiety \& post-prandial fullness). For at least more than 3 month, history of intake of antibiotics for eradication of $\mathrm{H}$. pylori taken for confirmation of H.pylori. Remaining biopsy specimens send for histopathological examination.

After history and clinical examination, patient underwent USG abdomen ,Upper GI Endoscopy . During endoscopy, site of the lesion and macroscopic type of the lesions were identified and recorded. Multiple tissue biopsies (>10) were collected from non-necrosed region of cancer. One piece of each paired specimen were immediately subjected to RapidUrease Test dry kit (RUT) for detection of Helicobacter pylori.Further this biopsy specimen were subjected to modified giemsa stainingand culture.

\section{OBSERVATION AND RESULTS}

Table .1. Prevalence Of H.pylori

\begin{tabular}{|c|c|c|}
\hline H PYLORI & No. OF PATIENTS & \% \\
\hline Present & 45 & 64.29 \\
\hline Absent & 25 & 35.71 \\
\hline
\end{tabular}


Total

70

100

In our study, 70 cases of gastric carcinoma were taken out of which 45 patients $(64.29 \%)$ were positive for $\mathrm{H}$ pylori infection

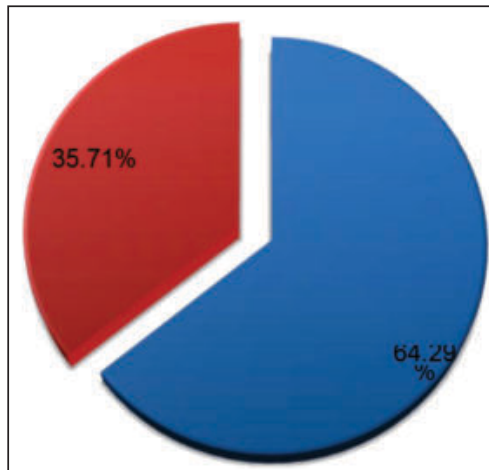

$\square$ Present absent

Figure 1:- Showing The Prevalence Of H.pylori In Gastric Carcinoma

Table.2.Symptoms

\begin{tabular}{|c|c|c|c|c|}
\hline SYMPTOIMS & NO.OF & \multicolumn{2}{|c|}{ H PYLORI } & \\
\cline { 3 - 5 } & PATIENT & Present & Absent & p value \\
\hline Dysphagia & $23(100 \%)$ & $17(73.91 \%)$ & $6(26.09 \%)$ & 0.24 \\
\hline Anorexia & $24(100 \%)$ & $14(58.33 \%)$ & $10(41.67 \%)$ & 0.45 \\
\hline Weight Loss & $43(100 \%)$ & $30(69.77 \%)$ & $13(30.23 \%)$ & 0.23 \\
\hline Vomiting & $53(100 \%)$ & $34(64.15 \%)$ & $19(35.85 \%)$ & 0.96 \\
\hline $\begin{array}{c}\text { Epigastric } \\
\text { Pain }\end{array}$ & $63(100 \%)$ & $39(61.9 \%)$ & $24(38.09 \%)$ & $<0.001$ \\
HS
\end{tabular}

It was observed that epigastric pain was the most common symptom followed by vomiting and weight loss in patients with gastric carcinoma. Most of the patients showed $\mathrm{H}$ pylori positivity with these symptoms. (Table 2 ). On examination, 36 patients had palor as well as lump abdomen among which $55.56 \%$ patients had $\mathrm{H}$ pylori infection.(Table 3 )

\section{Table.3.signs}

\begin{tabular}{|c|c|c|c|c|}
\hline \multirow{2}{*}{ SIGNS } & & \multicolumn{2}{|c|}{ H PYLORI } & \\
\cline { 2 - 5 } & No of patients & Present & Absent & p value \\
\hline Lump & $16(100 \%)$ & $12(75 \%)$ & $4(25 \%)$ & 0.31 \\
\hline Pallor & $18(100 \%)$ & $13(72.22 \%)$ & $5(27.78 \%)$ & 0.41 \\
\hline Lump+Pallor & $36(100 \%)$ & $20(55.56 \%)$ & $16(44.44 \%)$ & 0.11 \\
\hline p value & & \multicolumn{3}{|c|}{$0.29 \mathrm{NS}$} \\
\hline
\end{tabular}

Table. 4. Type Of Lesion

\begin{tabular}{|c|c|c|c|c|}
\hline TYPE OF & NO OF & \multicolumn{2}{|c|}{ H PYLORI } & \\
\cline { 3 - 5 } LESION & PATIENTS & Present & Absent & p value \\
\hline Polypoid & $8(100 \%)$ & $4(50 \%)$ & $4(50 \%)$ & 0.37 \\
\hline $\begin{array}{c}\text { Ulcero } \\
\text { proliferative }\end{array}$ & $28(100 \%)$ & $20(71.43 \%)$ & $8(28.57 \%)$ & 0.31 \\
\hline Ulcerative & $34(100 \%)$ & $21(61.76 \%)$ & $13(38.24 \%)$ & 0.67 \\
\hline p value & & $0.39 \mathrm{NS}$ & & \\
\hline
\end{tabular}

Table. 5. Histological Type Oflesion

\begin{tabular}{|c|c|c|c|c|}
\hline $\begin{array}{c}\text { HISTOLOGICA } \\
\text { L TYPE }\end{array}$ & $\begin{array}{c}\text { NO. OF } \\
\text { PATIENTS }\end{array}$ & \multicolumn{2}{|c|}{ H PYLORI } & \\
\hline $\begin{array}{c}\text { Signet cell } \\
\text { Adenocarcinoma }\end{array}$ & $3(100 \%)$ & $2(66.67 \%)$ & $1(33.33 \%)$ & 0.92 \\
\hline $\begin{array}{c}\text { Mucinous } \\
\text { Adenocarcinoma }\end{array}$ & $3(100 \%)$ & $2(66.67 \%)$ & $1(33.33 \%)$ & 0.92 \\
\hline $\begin{array}{c}\text { Moderately } \\
\text { differentiated } \\
\text { Adenocarcinoma }\end{array}$ & $10(100 \%)$ & $6(60 \%)$ & $4(40 \%)$ & 0.76 \\
\hline $\begin{array}{c}\text { Well } \\
\text { Differentiated } \\
\text { Adenocarcinoma }\end{array}$ & $19(100 \%)$ & $13(68.42 \%)$ & $6(31.58 \%)$ & 0.66 \\
\hline $\begin{array}{c}\text { Poorly } \\
\text { Differentiated } \\
\text { Adenocarcinoma }\end{array}$ & $35(100 \%)$ & $22(62.86 \%)$ & $13(37.14 \%)$ & 0.80 \\
\hline
\end{tabular}

In our study, ulcerative lesions ( 34 patients) were more common in gastric carcinoma patients but ulceroproliferative lesions had higher incidence of $\mathrm{H}$ pylori infection(71.43\%) as compared to ulcerative lesion group (61.76\%). ( Table 4$)$. We found that, of 70 cases, the most common histological type in gastric carcinoma was was poorly differentiated adenocarcinoma seen in 35 cases (50\%). Also the most common histological type in gastric carcinoma positive for $\mathrm{H}$. pylori infections was poorly differentiated adenocarcinoma seen in 22 case $(62 \%)$ (Table5).

\section{DISCUSSION}

\section{Prevalence}

We found that out of 70 cases of gastric carcinoma 45 cases $(64.29 \%)$ were positive for H.pylori. It is comparable to study by Talukdar et al (1995) ${ }^{5}$, MA Kabir et al (2006) ${ }^{6}$, Mishra et al $(2007)^{7}$, NG. Javan, Wormi Sharon $(2016)^{8}$ in which prevalence of $\mathrm{H}$ pylori was more than $60 \%$ in gastric carcinoma patients.

\section{Age And GenderWise Distribution}

We found that, out of 70 cases, most of the cases of gastric carcinoma $(73.08 \%)$ who were positive for $\mathrm{H}$. pylori were seen after the 6th decade of life. It was also observed that males $(69.23 \%)$ were affected more than females. It is similar to other studies by Lark-Eris Hansson et al (1989-1991, Sweden $)^{9}$, Hajime yamagata et al (1988 japan) ${ }^{10}$, MA Kabir et al (2006) ${ }^{6}$, Shelat VG et al (2012) ${ }^{11}$, Ashish Kumar et al $(2013){ }^{12}$, Chrungoo et al (2015) ${ }^{13}$, Yakoob J et al (2017) ${ }^{14}$ who had same age of distribution

\section{Symptoms}

We found that out of 70 cases, the most common symptom in gastric carcinoma was epigastric pain (63 cases / 90\%) followed by vomiting (53 cases / 75.7\%), also the most common symptom in carcinoma cases positive with H. pylori infections was pain (39 cases / 61.9\%) followed by vomiting (34 cases $/ 64.15 \%$ ). In studies by Ashish Kumar et al. (2013) ${ }^{12}$ Chrungoo et al. (2015) $)^{13}$ the most common symptom was abdominal pain, whereas in studies of Qurieshi et al(2011)15, MA Kabir et al(2006)6 the most common symptom was dyspepsia.

\section{Signs}

We noted that the most common sign noted in gastric carcinoma patients positive for H. pylori was lump and pallor (20cases). This is comparable to studies by MA Kabir et al (2006) ${ }^{6}$ and Hire Pratik et al. (2017) ${ }^{16}$ where the most common sign was abdominal lump. whereas in study by Chrungoo et al.(2015) ${ }^{13}$ most common sign was pallor

\section{Site Of Lesion}

We found that, out of 70 cases, most common site for gastric carcinoma was antrum and pyloric region seen in 49 cases $(70 \%)$. It is similar to studies by MA Kabir et al(2006) Ashish Kumar et al(2013) ${ }^{12}$ where most common site was antrum.

\section{Type Of Lesion}

We found that, of the 70 cases, the most common type of lesion in gastric carcinoma was ulcerative followed by ulceroproliferative and the most common type of lesion positive for $\mathrm{H}$. pylori infections in gastric carcinoma was ulceroproliferative lesion seen in 20 cases (71.43\%), followed by ulcerative lesion seen in 2 l cases(61.76\%). Ulcerative lesion was most common according to studies conducted by MA Kabir et al(2006) ${ }^{6}$; Ashish Kumar et al(2013) ${ }^{12}$.

\section{Histological Type Of Lesion}

We found that, of 70 cases, the most common histological type in gastric carcinoma was was poorly differentiated adenocarcinoma seen in 35 cases (50 \%). Also the most common histological type in gastric carcinoma positive for $\mathrm{H}$. pylori infections was poorly differentiated adenocarcinoma seen in 22 cases $(62 \%)$. MA Kabir et al (2006) ${ }^{6}$, reported that out of 50 patients, histopathologically $52 \%$ was intestinal 
type, $28 \%$ was diffuse type $20 \%$ was poorly differentiated adenocarcinoma. The prevalence of $\mathrm{H}$. pylori in overall carcinoma stomach cases was $60 \%$ but individually in intestinal type $88 \%$, in diffuse type $57 \%$ and in poorly differentiated type 50\%. Similarly M.kato et al (2004) ${ }^{17}$, in a multicentric study found that H.pylori was associated more with both intestinal and diffuse type of gastric carcimnoma. Xia Wang et al (2014) ${ }^{18}$ concluded from their studies that there was significant association of H.pylori infection and well differentiated adenocarcinoma.

\section{CONCLUSION}

On the basis of our study it is evident that h.pylori is the independent risk factor for gastric carcinom. Infection with $\mathrm{H}$. pylori causes chronic inflammatory reactions and therefore increases the risk of developing duodenal ulcer, gastric ulcer disease and Gastric carcinoma. H. pylori infection is one of the strongest known risk factors for Gastric carcinoma.

\section{REFERENCES}

1. Ferlay J, Shin HR, Bray F, Forman D, Mathers C, Parkin DM. Estimates of worldwide burden of cancer in 2008: GLOBOCAN 2008. International journal of cancer.2010 Dec 15;127(12):2893-917..

2. Kalyani R,Das S, Kumar M. $\square$ Pattern of cancer in adolescent and young adults-a ten year study in India. $\square$ Asian Pac J Cancer Prev 1 1 (2010):655-9.

3. Schistosomes, liver flukes and Helicobacter pylori. IARC Working Group on the Evaluation of Carcinogenic Risks to Humans. Lyon, 7-14 June 1994. IARC Monogr Eval Carcinog Risks Hum. 1994;61:1-241. [PubMed] [Google Scholar]

4. Deen NS, Huang SJ, Gong L, Kwok T, Devenish RJ. The impact of autophagic processes on the intracellular fate of Helicobacter pylori: more tricks from an enigmatic pathogen? Autophagy. 2013;9:639-652. [PMC free article] [PubMed] [Google Scholar]

5.. Talukder SG. Association of Helicobacter pylori with gastric cancer and other gastroduodenal lesions (Thesis). Dhaka:University of Dhaka, 1995.

6. Kabir MA, Barua R, Masud H, Ahmed DS, Islam MM, Karim E, Sarker MN, Barman RC. Clinical presentation, histological findings and prevalence of Helicobacter pylori in patients of gastric carcinoma. Faridpur Medical College Journal.2011;6(2):78-81.

7. Misra V, Misra SP, Singh MK, Singh PA, Dwivedi M. Prevalence of H. pylori in patients with gastric cancer. Indian J Pathol Microbiol. 2007;50:702- 707. [PubMed] [Google Scholar

8. Javan NG, Sharon W. Association of Helicobacter pylori infection and stomach cancer: our experience. International Surgery Journal. 2018 Jul 24;5(8):27948.

9. Hansson LE, Engstrand L, Nyrén O, Lindgren A. Prevalence of Helicobacter pylori infection in subtypes of gastric cancer. Gastroenterology. $1995 \mathrm{Sep}$ $1 ; 109(3): 885-8$

10. Yamagata H, Kiyohara Y, Aoyagi K, Kato I, Iwamoto H, Nakayama K, Shimizu H, Tanizaki Y, Arima H, Shinohara N, Kondo H. Impact of Helicobacter pylori infection on gastric cancer incidence in a general Japanese population: the Hisayama study. Archives of internal medicine. 2000 Jul 10;160(13):1962-8.

11. Vishal G Shelat, Juin Fong Thong, Melanie Seah, et al. Role of staging laparoscopy in gastric malignancies - our institutional experience. World J Gastrointest Surg. 2012;4:214-219.

12. Ashis Kumar Saha, Somnath Maitra, Subhas Chandra Hazra. Epidemiology of gastric cancer in the Gangetic areas of West Bengal. ISRN Gastroenterol. 2013;2013:823483

13. Chrungoo RK, Mala TA, Gupta R, et al. Role of laparoscopic surgery in cancer of stomach:Our early experience. Int J Cancer Ther Oncol. 2015;3:3320.

14. Abbas Z, Khan HA, Awan S, Ahmad Z. Distribution of gastric carcinoma in an area with a high prevalence of Helicobacter pylori. The Turkish journal of gastroenterology: the official journal of Turkish Society of Gastroenterology.. 2017;28(2):98

15. Qurieshi MA, Masoodi MA, Kadla SA, et al. Gastric cancer in Kashmir. Asian Pac J Cancer Prev. 2011;12:303-307.

16. Hire P, Golhar KB. Role of Staging Laparoscopy in Gastric Carcinoma. International Journal of Advance Research, Ideas and Innovations in Technology. 2017;3:204-214

17. Kato M, Asaka M, Shimizu Y, Nobuta A, Takeda H, Sugiyama T, Members of the Multi.Centre Study Group. Relationship between Helicobacter pylori infection and the prevalence, site and histological type of gastric cancer. Alimentary pharmacology \& therapeutics. 2004 Jul;20:85-9

18. Wang X, Wei M, Sun Z. An association study of histological types of gastric carcinoma with Helicobacter pylori infection. Cell biochemistry and biophysics. 2014 Nov 1;70(2):1283-7. 